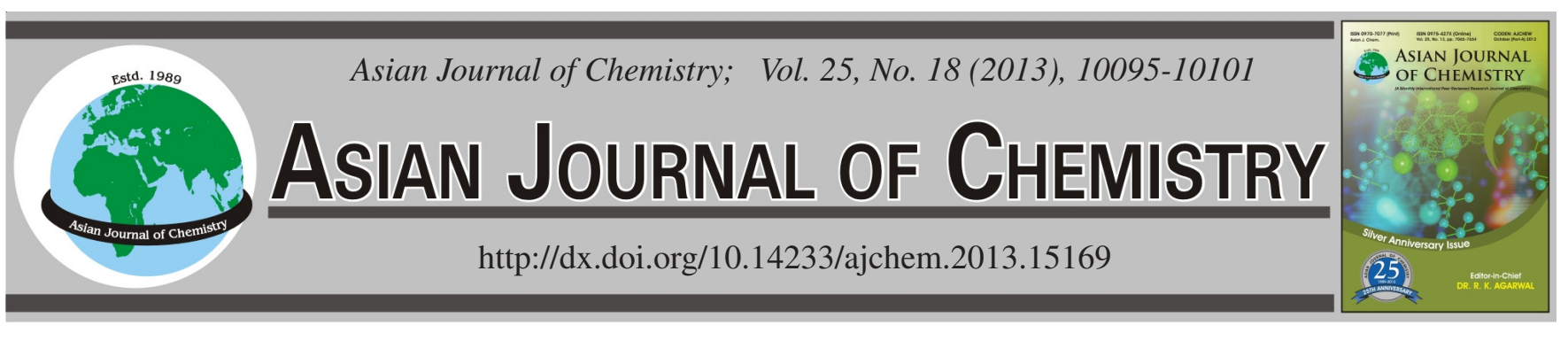

\title{
Characteristic of Dissolved Organic Matters Removal from Bio-Treated Effluents of Textile and Dyeing Wastewater by Coagulation Enhanced with $\mathrm{KMnO}_{4}$
}

\author{
Mu Li ${ }^{1,2}$, Xianbo Sun ${ }^{1}$, Feiyue Qian ${ }^{1}$, Hongyong Xu' ${ }^{1}$ and Yongdi Liu ${ }^{1, *}$
}

\begin{abstract}
${ }^{1}$ School of Resources and Environmental Engineering, East China University of Science and Technology, Shanghai 200237, P.R. China ${ }^{2}$ State Key Laboratory of Pollution Control and Resources Reuse, School of Environmental Science and Engineering, Tongji University, Shanghai 200092, P.R. China
\end{abstract}

*Corresponding author: E-mail: ydliu@ecust.edu.cn

(Received: 17 January 2013;

Accepted: 7 November 2013)

AJC-14343

\begin{abstract}
In this paper, the effectiveness of coagulation enhanced with $\mathrm{KMnO}_{4}$ for removal of dissolved organic matter from bio-effluent of textile and dyeing wastewater was investigated. Under the optimal dosing conditions, coagulation enhanced with $\mathrm{KMnO}_{4}$ had better American Dyeing Manufactures Institute value (ADMI $\left.{ }_{7.6}\right)$ and removal of dissolved organic carbon (83\% versus $72 \%$; $40 \%$ versus $36 \%$ ) than magnesium sulphate coagulation alone. The results of XAD-8/XAD-4 tandem resin fractionation and molecular weight distribution measurements demonstrated that the removal of hydrophobics, transphilics and large-molecular weight organics were improved by enhanced coagulation, the $\mathrm{ADMI}_{7.6}$ value was $40 \%$ lower than the effluent of magnesium sulphate coagulation alone. Moreover, the hydrophilics and low-MW (<1 K Da) organics in the effluent of enhanced coagulation were increased by 39 and $145 \%$, respectively, which were the main reasons for inconspicuous improvement of dissolved organic carbon removal. Qualitative analysis on dissolved organic matter with three-dimensional excitation emission matrix fluorescence spectroscopy (3-DEEMs) indicated that the colour-caused matters, fulvic-like and humic-like organics were further removed during enhanced coagulation process. Meanwhile, the increased low-molecular weight hydrophilics were protein-like and fulvic-like organics dominantly. Coagulation enhanced with $\mathrm{KMnO}_{4}$ should be combined with additional treatment steps that specialized in removing the remained dissolved organic matter (mostly molecular weight $<1 \mathrm{~K} \mathrm{Da}$, hydrophilic) to produce a high removal performance.
\end{abstract}

Key Words: Textile and dyeing wastewater, Bio-treated effluents, Dissolved organic matter, Enhanced coagulation.

ᄂ - - - - - - - - - - - - - - - - - - - - - - - - - - - - -

\section{INTRODUCTION}

The wastewater originated from textile and dyeing industry contain various pollutants including a high content of organic matter and colour problem depending on forms of dyes, surface active material and textile and dyeing additives materials used in the processes ${ }^{1}$. Full-scale operation and laboratory studies have been carried out to assess the biological treatment of textile and dyeing wastewater, however, there exists organics removal limitation due to the complicated aromatic structures and low biodegradability of dyes and textile chemicals ${ }^{2-5}$. The direct discharge of these bio-treated effluents into environment affects ecological status and impacts the receiving water systems by causing various undesirable changes ${ }^{6-8}$. Therefore, in view of compliance with increasingly stringent legislation on the discharge of textile and dyeing wastewater, post-treatment of bio-treated effluents for organic pollutants removal and decolorization become a necessity.

The available literature shows a large number of wellestablished organics removal and decolorization methods and among them, chemical coagulation is employed as one of the most practised technology for yielding high organic matters removal and decolorization efficiency ${ }^{9,10}$. Ferric and alum are presently the most widely used coagulant ${ }^{11}$ and have been applied extensively on the treatment of textile and dyeing wastewater ${ }^{11-14}$. Nowadays, interests have increased on the aspect of using magnesium as a potential coagulant for the chemical clarification of wastewater ${ }^{15,16}$. However, the currently researches focus on treating the crude wastewater of textile and dyeing industries, synthetic wastewater contained some certain kinds of targeted dyes through magnesium coagulation processes monotonously ${ }^{9,16,17}$. The treatment of bio-treated effluents of textile and dyeing wastewater by magnesium coagulation is yet not reported.

Potassium permanganate is a powerful oxidizing agent. Owing to its comparative stability and relatively low cost, potassium permanganate has been widely used for heavy metal removal $^{18}$, algal coagulation enhancement ${ }^{19}$, antibiotic ${ }^{20}$ and endocrine disrupting chemicals ${ }^{21}$ oxidation during water treatment and underground water rehabilitation. Other studies were 
carried out to investigate the oxidation efficiency on wastewater contained different type of dyes ${ }^{22,23}$. In addition, $\mathrm{KMnO}_{4}$ can serve as a coagulant aid to enhance the coagulation performance because of its reduction product hydrated manganese dioxides $\left(\delta \mathrm{MnO}_{2}\right)^{24-26}$. Up to now, there is no report published about the oxidation and removal enhancement of dissolved organic matters (DOM) in bio-treated effluents of textile and dyeing wastewater by magnesium coagulation enhanced with $\mathrm{KMnO}_{4}$.

In this paper, the effectiveness of coagulation enhanced with $\mathrm{KMnO}_{4}$ process for removal of dissolved organic matter from bio-effluent of dyeing and textile wastewater was investigated. The purpose of this study is to characterize and compare the removal behaviors of DOM fractions isolated from biologically treated effluent samples during the magnesium sulphate coagulation alone and coagulation enhanced with $\mathrm{KMnO}_{4}$. XAD-8/XAD-4 tandem resin fractionation, molecular weight (MW) distribution and three-dimensional excitationemission matrix spectroscopy (3-DEEMs) were applied to understand the characterization of DOM fractions and removal performance during the coagulation process. The impact of polarity (hydrophobic/hydrophilic) and MW distribution of DOM in the bio-treated effluents of textile and dyeing wastewater on coagulation were also discussed.

\section{EXPERIMENTAL}

Water samples: The bio-treated effluent samples were collected from the secondary clarifier of a textile and dyeing wastewater treatment plant (traditional activated sludge process) in Kunshan, Jiangsu province, China. The characteristics of the samples are presented in Table-1. These effluent indexes fitted the national integrated wastewater discharge standard of China (GB 8978-1996).

\begin{tabular}{cc}
\multicolumn{3}{c}{ TABLE-1 } \\
QUALITIES OF BIO-TREATED EFFLUENT \\
\hline Parameter & Range \\
\hline $\mathrm{pH}$ & $8.16-8.66$ \\
$\mathrm{SCOD}(\mathrm{mg} / \mathrm{L})$ & $54-74$ \\
$\mathrm{DOC}(\mathrm{mg} / \mathrm{L})$ & $20.81-26.40$ \\
$\mathrm{UV}_{254}\left(\mathrm{~cm}^{-1}\right)$ & $0.961-1.048$ \\
Dilution ratio $($ folds $)$ & $25-30$ \\
ADMI $_{7.6}$ value & $266-295$ \\
\hline
\end{tabular}

Analytical methods: Samples before and after treatments were first filtered by a $0.45 \mu \mathrm{m}$ microfilter. The dissolved organic carbon (DOC) measurement was conducted with a German Element liquid TOC analyzer. $\mathrm{UV}_{254}$ (UV absorbance at 254 $\mathrm{nm}$ ) was measured with a Unico UV2100 UV/visible spectrometer using $1 \mathrm{~cm}$-long quartz cells. And all samples were acidified to $\mathrm{pH} 2$ with $\mathrm{HCl}$ before the $\mathrm{UV}_{254}$ measurements. SCOD measurements were made using a HACH digital reactor block 200 (DRB200) and DR 2800 spectrophotometer.

Colour measurement by American Dyeing Manufactures Institute method: In china, the industrial wastewater colour measurement method being used is dilution multiple method (GB 11903-89). This method depends largely on visual observation that will bring subjective error to the measuring. Compared with dilution multiple, the 31 wavelength (WL) ADMI method can offer accurate definition of wastewater colour $^{27}$ and have been widely applied in American, Britain and our Taiwan district ${ }^{28-30}$. The 31 WLADMI value is determined spectrophotometrically, using a spectrophotometer with a 10 $\mathrm{nm}$ spectral band and an effective operating range of 400-700 $\mathrm{nm}$. Our former researches found that there existed a good correlation between dilution multiple and ADMI value and ADMI measurement can be adopted as a better substitute ${ }^{31}$. HACH DR4000U was used for ADMI measurement (Program 1660 ) and sample should be filtered by a $0.45 \mu \mathrm{m}$ microfilter to remove the turbidity and $\mathrm{pH}$ was adjusted to 7.6 (in term of $\mathrm{ADMI}_{7.6}$ ) before measurement.

Dissolved organic matter fractionation method: The DOM fractionation method used in this study was derived from the procedure developed by Croue et $a .^{32}$. Dissolved organic matter was fractionated into hydrophobic acids, non-acid hydrophobics, transphilics and hydrophilics using Amberlite XAD- 8 and XAD-4 resins. The detailed preparation and fractionation steps were according to Gong et $a l .{ }^{33}$. A flow chart of the DOM fractionation procedure is shown in Fig. 1. The fractionation procedure was applied to both untreated and treated samples. After fractionation, DOC and $\mathrm{ADMI}_{7.6}$ were measured for DOM fractions 1-4. Resins were changed after filtration of each sample.

$$
\text { Filtered water }(0.45 \mu)
$$

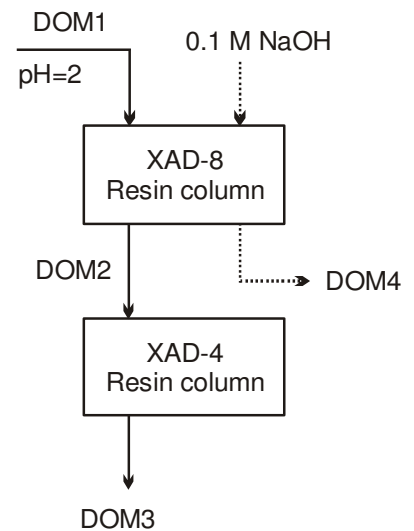

Fig. 1. Flow chart of DOM fractionation procedure

Each DOM fraction was calculated as follows: Hydrophobic acids = DOM4

Non-acid hydrophobics = DOM1-DOM2 - DOM4 (2)

Transphilics = DOM2 - DOM3

Hydrophilics = DOM3

Molecular weight distribution method: Molecular weight (MW) distribution was measured using a stirred ultra-filtration cell with a volumetric capacity of $300 \mathrm{~mL}$ (SCM-300), operating under positive pressure $\left(0.25-0.30 \mathrm{MPa} ; \mathrm{N}_{2}\right.$ as the drive gas). The samples were filtered on membrane discs that have MW cut-off sizes of 1, 4, 10 and $50 \mathrm{~K} \mathrm{Da}$ (made of PES). Ultra-pure water was used for blank samples. Aliquots of samples that were collected after each filtration step were subsequently subjected to DOC and $\mathrm{ADMI}_{7.6}$ measurement.

3-DEEMs: 3-DEEMs were recorded using a Cary-eclipse fluorescence spectrophotometer (Varian US) equipped with a $150 \mathrm{~W}$ Xe-arc lamp source, which displayed a maximum emission intensity of 1000 arbitrary units (AU). A wavelength step size of $10 \mathrm{~nm}$ was used for collection of 3-DEEMs. The excitation 
wavelength $\left(\lambda_{\text {ex }}\right)$ range was from 200 to $400 \mathrm{~nm}$ and the emission wavelength $\left(\lambda_{\text {em }}\right)$ range was from $300-550 \mathrm{~nm}$. All spectra were collected with a $5 \mathrm{~nm}$ band pass on both emission and excitation wavelength. PMT voltage was set at $600 \mathrm{~V}$ and the scanning speed was $1200 \mathrm{~nm} / \mathrm{min}$. Spectrums for all samples were obtained at original $\mathrm{pH}$ and the water Raman peak was used for 3-DEEMs intensity normalization.

Experimental procedure: Magnesium sulphate coagulation alone and coagulation enhanced with $\mathrm{KMnO}_{4}$ were conducted by a jar test procedure. Diluted solutions of $\mathrm{HCl}$ and $\mathrm{NaOH}$ were used to adjust the $\mathrm{pH}$ of the bio-treated effluents to the desired $\mathrm{pH}$. Reagent grade magnesium sulphate $\left(\mathrm{MgSO}_{4} \cdot 7 \mathrm{H}_{2} \mathrm{O}\right)$ and potassium permanganate $\left(\mathrm{KMnO}_{4}\right)$ were used. $400 \mathrm{~mL}$ beakers, containing $200 \mathrm{~mL}$ bio-treated effluents, were placed on a six-position mechanical stirrer. Samples were adjusted to a certain $\mathrm{pH}$ before potassium permanganate was added, at the stirring speed of $60 \mathrm{rpm}$. The duration of preoxidation was 10-60 min. After the pre-oxidation stage, the coagulant, magnesium sulphate and the waste were mixed for a $1 \mathrm{~min}$ period of fast stirring at $120 \mathrm{rpm}$, then followed by a $15 \mathrm{~min}$ period of slow stirring at $60 \mathrm{rpm}$ and $15 \mathrm{~min}$ of sedimentation. An aliquot of supernatant was taken by a $0.45 \mu \mathrm{m}$ filtration for further analysis after settling.

The optimum $\mathrm{pH}$ value and dosages of magnesium sulphate coagulation alone required for DOM removal determined by jar test were: $\mathrm{pH}=12.0 ; 300 \mathrm{mg} / \mathrm{L}^{34}$. According to our previously published paper $^{35}$, under the optimal dosing condition of magnesium sulphate, the optimum $\mathrm{pH}$ value and duration of pre-oxidation for coagulation enhanced with $\mathrm{KMnO}_{4}$ were observed as 3 and $10 \mathrm{~min}$, respectively, using $20 \mathrm{mg} / \mathrm{L}$ of $\mathrm{KMnO}_{4}$. Then the characteristics of different DOM fractions in each effluent were investigated and compared. All the experiments were conducted in duplicate and their average values were reported.

\section{RESULTS AND DISCUSSION}

Removal performance of DOM fractions by coagulation enhanced with $\mathrm{KMnO}_{4}$ : Under the optimal dosing conditions, DOM in effluents was fractionated into hydrophobic acids, non-acids hydrophobics, transphilics and hydrophilics by XAD-8/XAD-4 tandem resin fractionation. The removal of dissolved organic matter by coagulation alone and coagulation enhanced with $\mathrm{KMnO}_{4}$ in terms of DOC and $\mathrm{ADMI}_{7.6}$ (Fig. 2).

Fig. 2 shows that after the coagulation by magnesium sulphate alone, hydrophobic acids and non-acids hydrophobics fractions were decreased to 4.81 and $2.15 \mathrm{mg} / \mathrm{L}$ in term of DOC, resulted in 47 and $45 \%$ removal, respectively. The DOC of transphilics and hydrophilics were 2.57 and $4.01 \mathrm{mg} / \mathrm{L}$, only 6 and $21 \%$ of them were removed. And the DOC of this effluent was 13.54 $\mathrm{mg} / \mathrm{L}$, total DOC removal was $36 \%$. In term of $\mathrm{ADMI}_{7.6}$, the value of total sample and each fraction were 78, 33, 28, 14, 3; $72 \%$ of total sample, $72 \%$ of hydrophobic acids, $78 \%$ of non-acids hydrophobics, $82 \%$ of hydrophilics and $26 \%$ of transphilics were removed. Hydrophobics were observed obtain remarkable higher removal performance than other DOM fractions. These results indicated that the polarity (hydrophobic/ hydrophilic) of DOM had noticeable effect on magnesium sulphate coagulation. During the coagulation process, hydrophobics were inclined to be eliminated preferentially.

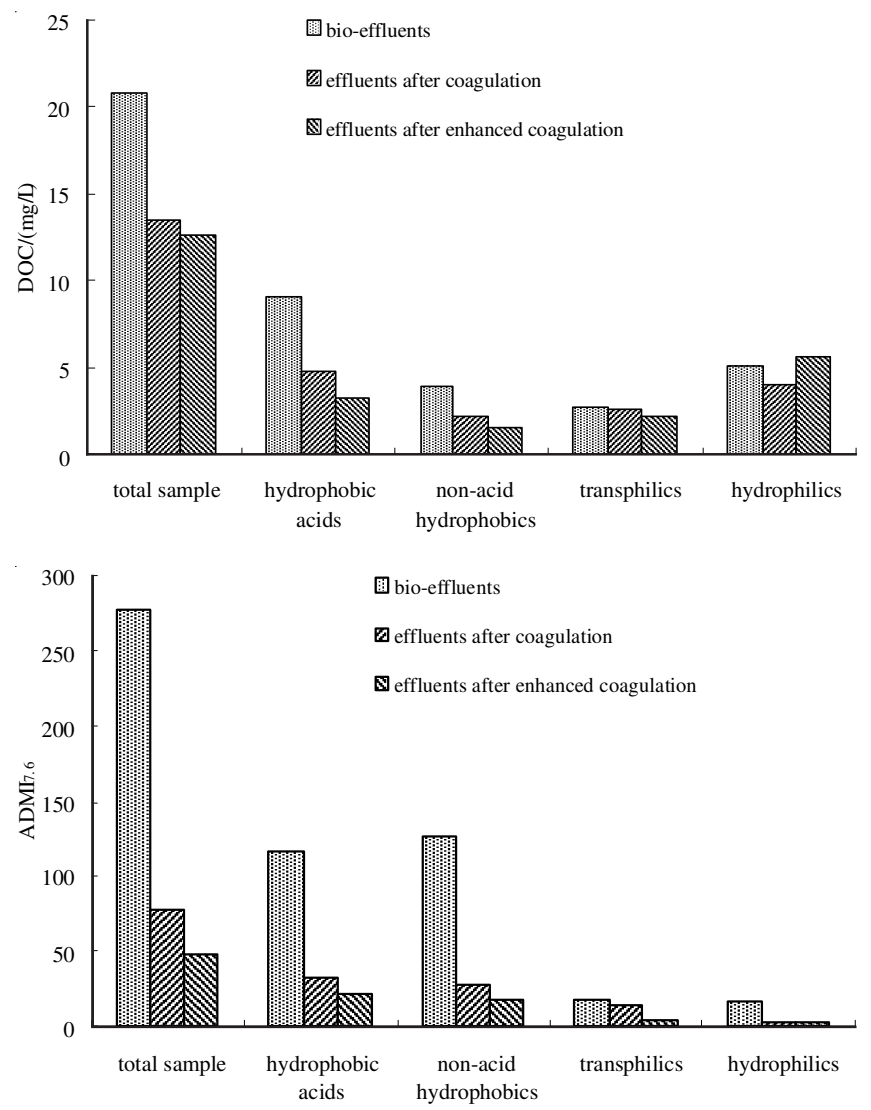

Fig. 2. Removal efficiency of DOM fractions by magnesium sulphate coagulation alone and coagulation enhanced with $\mathrm{KMnO}_{4}$

Otherwise, coagulation process had limited removal effect on the hydrophilics in this bio-treated effluent.

Another feature of Fig. 2 was that coagulation enhanced with $\mathrm{KMnO}_{4}$ improved the removal of DOM. For example, the total DOC and $\mathrm{ADMI}_{7.6}$ were $12.55 \mathrm{mg} / \mathrm{L}$ and 47,83 and $40 \%$ of them were removed, with 4 and $11 \%$ increased. By comparison, hydrophobic acids, non-acids hydrophobics and transphilics were further removed, the $\mathrm{DOC}$ and $\mathrm{ADMI}_{7.6}$ were $3.27,21,1.50$ and $19,2.20 \mathrm{mg} / \mathrm{L}$ and 4 , respectively and removal efficiencies were 64, 81, 64, 85, 20 and $80 \%$, accordingly. Obviously, both DOC and colour removal of hydrophobics and transphilics were further improved by enhanced coagulation. It was worth noting that the $\mathrm{ADMI}_{7.6}$ value of hydrophilics fraction was barely decreased. However, the concentration of hydrophilics (in term of DOC) was increased to $5.58 \mathrm{mg} / \mathrm{L}$ and $39 \%$ more than that by magnesium coagulation alone. The results suggested that the coagulation enhanced with $\mathrm{KMnO}_{4}$ generated more achromatous hydrophilics fraction, which couldn't be removed by coagulation process itself.

Coagulation process enhanced with $\mathrm{KMnO}_{4}$ was divided into three stages, before pre-oxidation (bio-effluents), after pre-oxidation and after coagulation. The changes of the organic fractions in terms of DOC and $\mathrm{ADMI}_{7.6}$ are presented in Fig. 3.

Fig. 3 demonstrated that the concentration and colour of hydrophobic acids, non-acids hydrophobics and transphilics were declined after the pre-oxidation stage. The concentration of hydrophilics was increased slightly while the colour dropped. Through the coagulation stage, the colour of all organic fractions and hydrophobic substances was further 

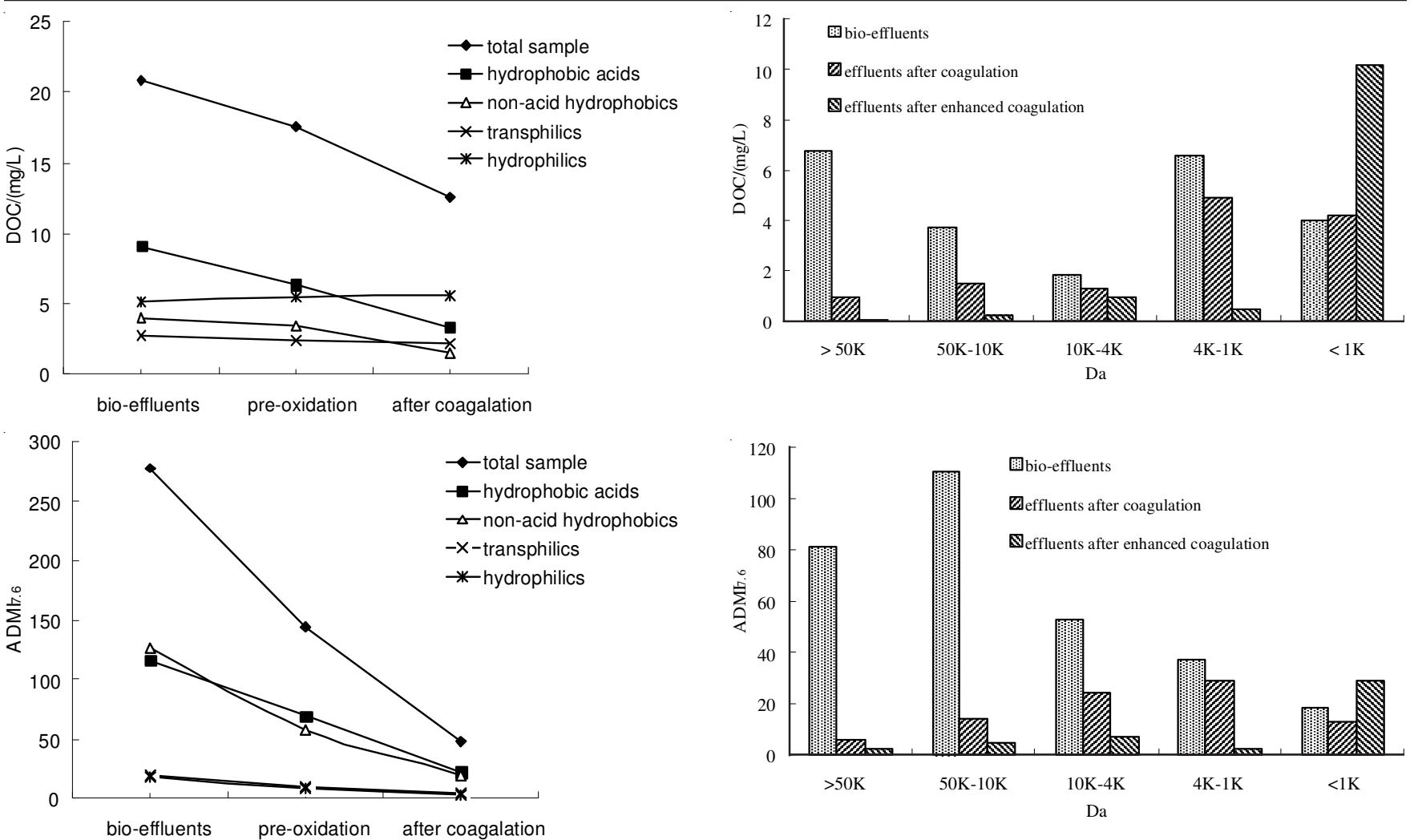

Fig. 3. Changes of DOM fractions during coagulation process enhanced with $\mathrm{KMnO}_{4}$

decreased. The concentration of hydrophilics increased slightly while transphilics still remained the same. It is concluded that the chromophores of organic fractions in this effluent were eliminated by the aromatic rings opening and bond breaking function $\mathrm{s}^{36}$ of potassium permanganate pre-oxidation. Meanwhile the pre-oxidation process changed the polarity (hydrophobic/hydrophilic) distribution of DOM, which generated more hydrophilic contents that resistant to remove.

Removal of different molecular weight organic fractions by coagulation enhanced with $\mathrm{KMnO}_{4}$ : Under the optimal dosing conditions, DOM in effluents was separated in five classes according to MW distribution: $>50,10-50,4-10,1-4$ and $<1 \mathrm{~K} \mathrm{Da}$. Removal of the different MW organic fractions by magnesium sulphate coagulation alone and coagulation enhanced with $\mathrm{KMnO}_{4}$ in terms of DOC and $\mathrm{ADMI}_{7.6}$ are illustrated in Fig. 4.

Fig. 4 showed that the organic matters with a MW of $>50$ $\mathrm{K} \mathrm{Da}$ in the raw sample were perfectly removed during the magnesium sulphate coagulation, the $\mathrm{DOC}$ and $\mathrm{ADMI}_{7.6}$ were $0.91 \mathrm{mg} / \mathrm{L}$ and 6, achieving a $87 \%$ reduction DOC and $93 \%$ of $\mathrm{ADMI}_{7.6 .}$. Similar with the $\mathrm{ADMI}_{7.6}$ removal, it was observed that DOC removal performance of organic fractions declined with the decrease of MW. As a result, there was almost no removal effect on organic matters with a $\mathrm{MW}$ of $<1 \mathrm{~K}$ Da in term of DOC ( $4.03 \mathrm{mg} / \mathrm{L}$ versus $4.15 \mathrm{mg} / \mathrm{L})$ and only $28 \%$ of $\mathrm{ADMI}_{7.6}$ (18 versus 13 ) was removed simultaneously. At high$\mathrm{pH}$ conditions ( $\mathrm{pH}$ values greater than 11.0), the formation of magnesium hydroxide precipitate/colloid provided a large adsorptive surface area and a positive superficial charge ${ }^{9,15,17}$, which suggested that large-MW organic fractions were more readily be removed by adsorptive coagulating mechanism.

Fig. 4. Removal of different MW organic fractions by magnesium sulphate coagulation alone and coagulation enhanced with $\mathrm{KMnO}_{4}$

Moreover, as seen from Fig. 4, the removal of all different MW organic matters (except for MW of $<1 \mathrm{~K} \mathrm{Da}$ ) by coagulation enhanced with $\mathrm{KMnO}_{4}$ had been improved, both DOC and $\mathrm{ADMI}_{7.6}$ of large-MW (>10 K Da) organic fractions were drastically diminished. On the other hand, low-MW $(<1 \mathrm{~K}$ Da) organic fractions increased to $10.15 \mathrm{mg} / \mathrm{L}$ (in term of DOC) in the final effluent and $145 \%$ more than the counterpart of magnesium coagulation alone. Considering the merely change of total DOC before and after the treatment, the increase of low-MW ( $<1 \mathrm{~K} \mathrm{Da})$ organic fractions might lead to inconspicuous improvement of DOC removal.

At every stages of coagulation process enhanced with $\mathrm{KMnO}_{4}$, changes of different MW organic fractions in terms of DOC and $\mathrm{ADMI}_{7.6}$ are presented in Fig. 5.

Changes of different MW organic factions shown in Fig. 5 have demonstrated that organic matters with a MW of $>1 \mathrm{~K}$ Da were partly oxidized to form various products with a MW of $<1 \mathrm{~K} \mathrm{Da}$, resulted in the rise of low-MW organic fractions both in DOC and colour after the pre-oxidation stage. Through the coagulation stage, large-MW fractions were further removed. Owing to the limited removal effect on low-MW fractions of coagulation process, low-MW ( $<1 \mathrm{~K} \mathrm{Da}$ ) organic fractions become the bulk component of the effluent. By these observation, together with the results obtained from XAD-8/ XAD-4 tandem resin fractionation, it is indicated that most of the low-MW DOM fractions dominated in the effluent were hydrophilics.

3-DEEMs of DOM Fractions during magnesium coagulation alone and coagulation enhanced with $\mathrm{KMnO}_{4}$ : Recent advances in fluorescence spectrophotometric analysis permits the rapid collection of fluorescence data from small 

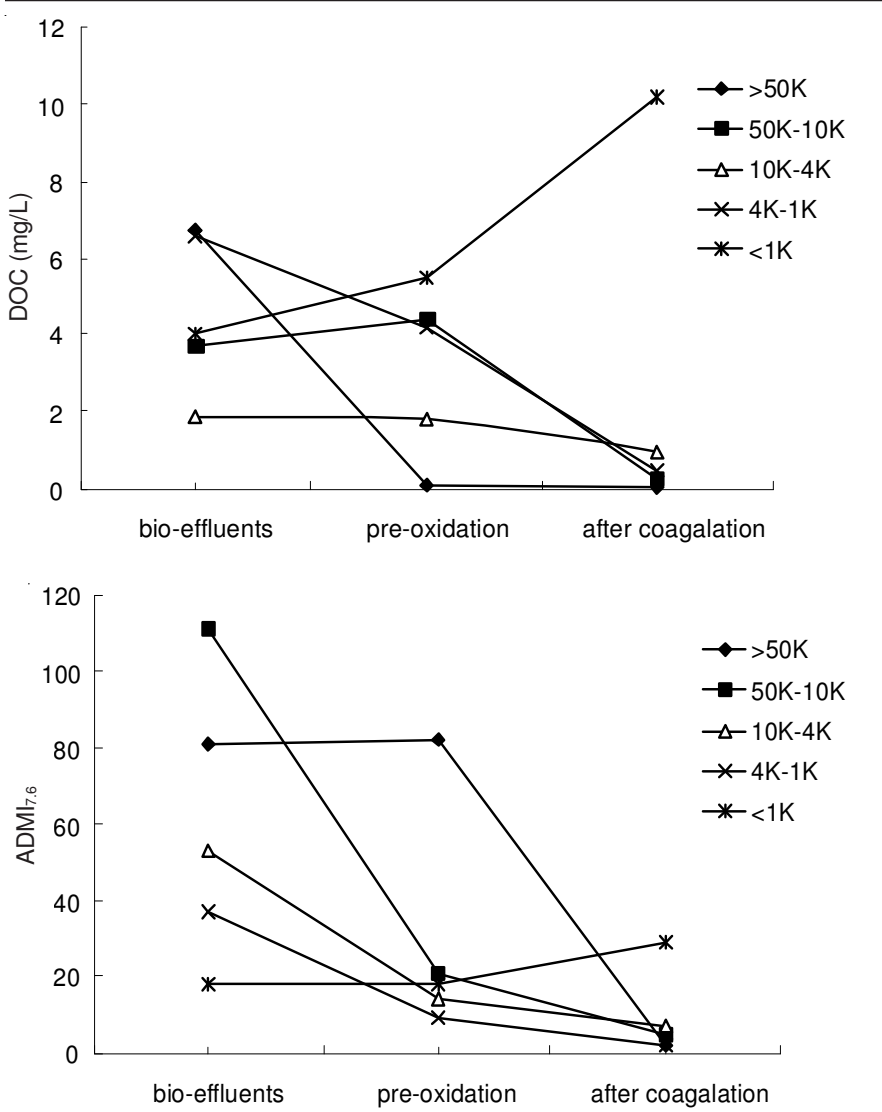

Fig. 5. Changes of different MW organic fractions during coagulation process enhanced with $\mathrm{KMnO}_{4}$

volume ( $5 \mathrm{~mL}$ or less) of wastewater samples at a higher optical resolution than previously possible and the generation of Excitation-Emission Matrix Spectroscopy (EEMs) by measuring across a range of excitation and emission wavelengths ${ }^{37,38}$. Although there was only $1 \%$ or less of the organic moieties in DOM actually emit light as fluorophores, 3-DEEMs is still an attractive analytical tool because it is at least an order of magnitude more sensitive to DOM than UV absorbance ${ }^{39}$. There are typically four major fluorescent components occurred in 3-DEEMs of wastewater reported by former researches ${ }^{40,37,39}$, humic-like fluorescence $\left(\lambda_{\mathrm{ex}} / \lambda_{\mathrm{em}}=350-440 \mathrm{~nm} / 430-510 \mathrm{~nm}\right)$, protein-like fluorescence $\left(\lambda_{\text {ex }} / \lambda_{\mathrm{em}}=240-290 \mathrm{~nm} / 300-350 \mathrm{~nm}\right)$, visible fulvic-like fluorescence $\left(\lambda_{\text {ex }} / \lambda_{\mathrm{em}}=310-360 \mathrm{~nm} / 370\right.$ $450 \mathrm{~nm})$ and UV fulvic-like fluorescence $\left(\lambda_{\mathrm{ex}} / \lambda_{\mathrm{em}}=240-270\right.$ $\mathrm{nm} / 370-440 \mathrm{~nm})$.

Under the optimal coagulation conditions, 3-DEEMs of effluents, hydrophobic acids and hydrophilics fractions obtained by XAD-8/XAD-4 tandem resin fractionation before and after magnesium sulphate coagulation alone and coagulation enhanced with $\mathrm{KMnO}_{4}$ are presented in Fig. 6 .

3-DEEMs of the bio-treated effluent obtained in Fig. 6(a) exhibited four fluorescence peaks, humic-like fluorescence $\left(\lambda_{\text {ex }} / \lambda_{\text {em }}=360-365 \mathrm{~nm} / 430-440 \mathrm{~nm}\right)$, protein-like fluorescence $\left(\lambda_{\text {ex }} / \lambda_{\text {em }}=265-295 \mathrm{~nm} / 310-345 \mathrm{~nm}\right)$, visible fulvic-like fluorescence $\left(\lambda_{\text {ex }} / \lambda_{\text {em }}=250-255 \mathrm{~nm} / 445-465 \mathrm{~nm}\right)$ and UV fulvic-like fluorescence $\left(\lambda_{\mathrm{ex}} / \lambda_{\mathrm{em}}=235-245 \mathrm{~nm} / 330-370 \mathrm{~nm}\right)$. The fluorescence intensity of protein-like and UV fulvic-like fluorophores were approximately equal ratio and both higher than the other two fluorophores. This distribution of fluorophores intensity indicated that protein-like and humiclike organic matters were the dominating part of DOM in this effluent. These results were comparable to the studies on NOM (Natural Organic Matters) and DOM of WWTP (Wastewater Treatment Plant) reported previously ${ }^{41-43}$. Despite overall similarity in 3-DEEMs before and after coagulation processes, nuances still existed among them. After magnesium coagulation alone, the protein-like and fulvic-like fluorescence peaks intensified while humic-like fluorescence decreased. Though the fluorescence intensity of protein-like and UV fulvic-like fluorescence increased through the $\mathrm{KMnO}_{4}$ pre-oxidation stage, the peaks area showed plateau value and the gross intensity declined markedly. It is worth mentioning that the visible fulvic-like fluorescence was even eliminated at this stage. After the coagulation enhanced with $\mathrm{KMnO}_{4}$, the peak intensity of protein-like and UV fulvic-like fluorophores increased continuously compared with the pre-oxidation stage, but they equaled to that of after the magnesium sulphate coagulation. Considering the increase of protein-like and UV fulvic-like fluorescences, the further decrease of humic-like fluorophores peak intensity and varnish of the visible fulviclike fluorescence with the improved $\mathrm{ADMI}_{7.6}$ value removal suggested that these two kinds of organics were the main colour-caused matters in the bio-treated effluent. The fluorescence intensity of some organics appeared intensification after the treatment in these 3-DEEMs could be attributed to the influence of the MW and polycondensation of aromatic compounds within DOM macromolecules ${ }^{42}$. According to DOM removal performance of different MW distribution, the low-MW organic fluorophores left in the final effluents gave higher intense emission fluorescence.

As seen from Fig. 6(b), the 3-DEEMs of hydrophobic acids fractions in different stages after XAD-8/XAD-4 tandem resin fractionation exhibited two fluorescence peaks, one attribute to UV fulvic-like fluorescence $\left(\lambda_{\mathrm{ex}} / \lambda_{\mathrm{em}}=260-275 \mathrm{~nm} /\right.$ $325-375 \mathrm{~nm})$ and another attributed to protein-like fluorescence $\left(\lambda_{\text {ex }} / \lambda_{\text {em }}=265-300 \mathrm{~nm} / 325-360 \mathrm{~nm}\right)$. For the bio-treated effluents, the fluorescence intensity of fulvic-like fluorophores was more intense than protein-like fluorophores, indicated that fulvic-like organic matters composed the majority of the hydrophobic acid fractions. The fluorescence intensity of protein-like increased notably after the magnesium sulphate coagulation, which possibly suggested that the effluent contained more low-MW protein-like organics. Through the $\mathrm{KMnO}_{4}$ pre-oxidation stage, the two fluorescence peak merely changed. However, the fluorescence intensity of fulvic-like and protein-like fluorophores decreased obviously after the coagulation enhanced with $\mathrm{KMnO}_{4}$ and exhibited lower intense than that after coagulation by magnesium sulphate alone. Fulvic-like organics were still the dominating component of the hydrophobic acid fractions and mostly low-MW matters through the whole treatment process. It is notable that some fluorophores gave higher fluorescence intensity than the counterparts before the resin fractionation, likely due to the greater proximity of condensed aromatic rings and other unsaturated bond systems and the consequent greater probability of deactivation of excited states by intra- and/or intermolecular bonding, internal self-quenching in higher MW $\operatorname{organics}^{42,44}$. 

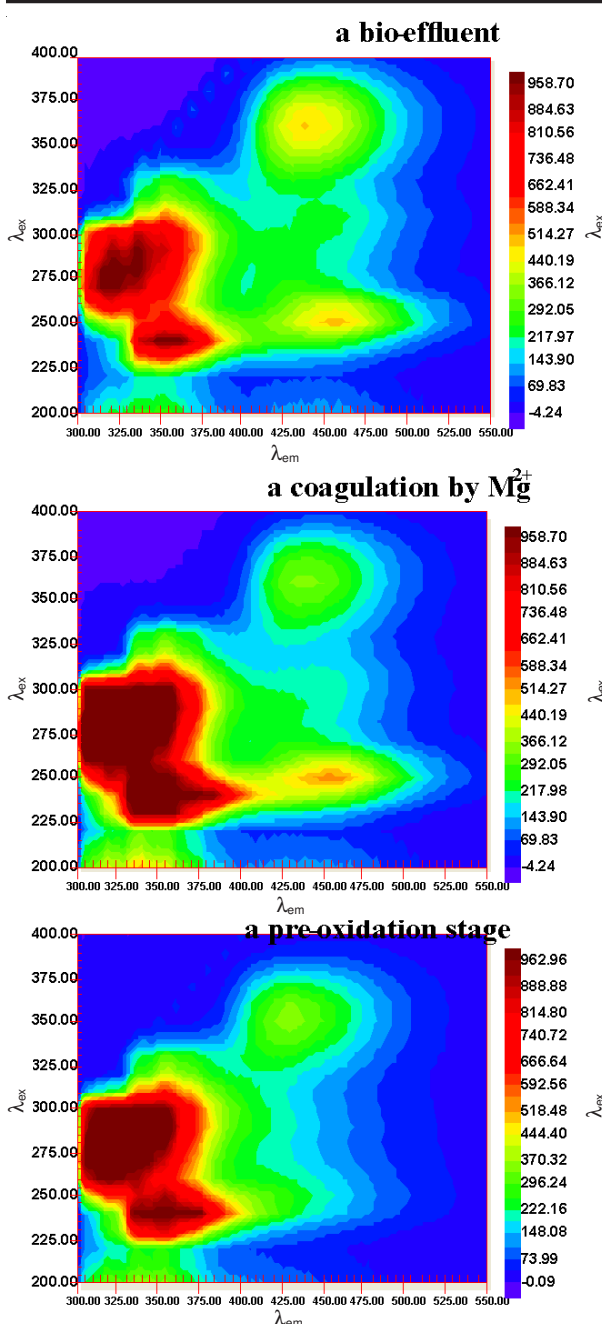

a enhances coagulation

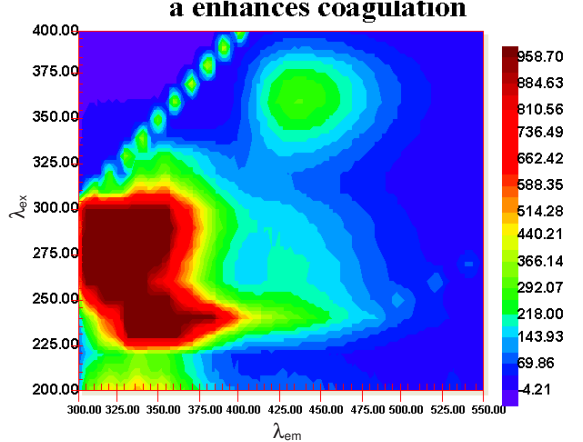

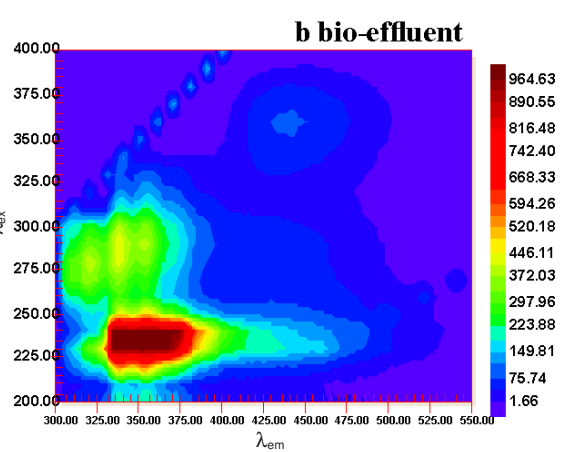

b coagulation by $\mathrm{Mg}^{+}$
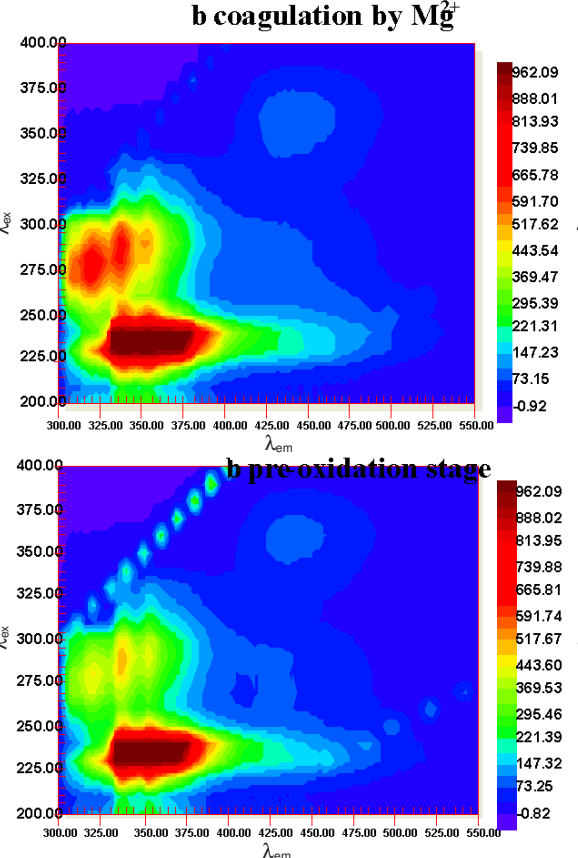

b enhanced coagulation

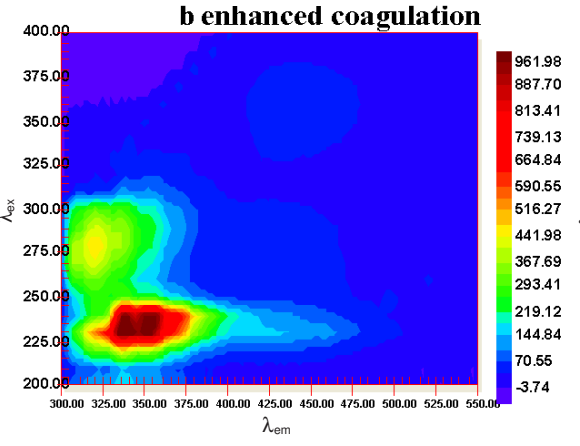

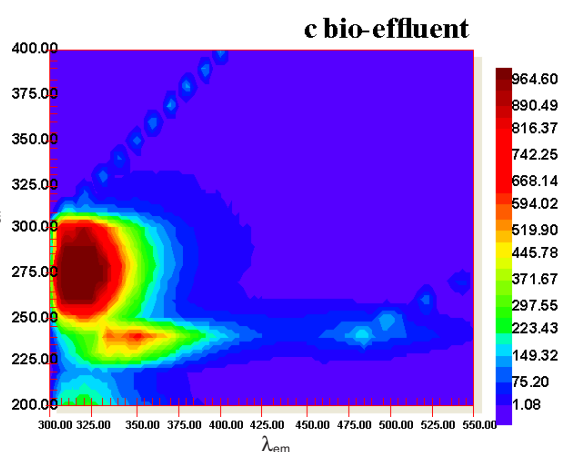

c coagulation by $\mathrm{Mg}^{+}$
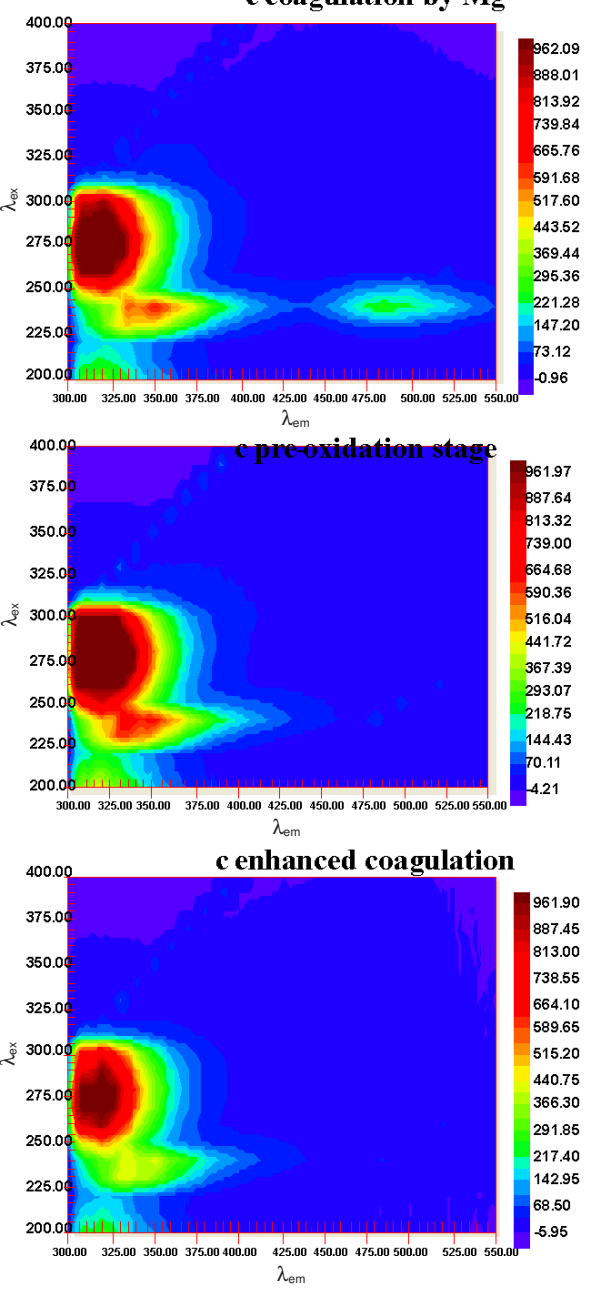

Fig. 6. 3-DEEMs of DOM Fractions of bio-treated effluent after magnesium sulphate coagulation and coagulation enhanced with $\mathrm{KMnO}_{4}$ (a: effluents of different stages; b: hydrophobic acids in different effluents; c: hydrophilics in different effluents)

3-DEEM of hydrophilics in the bio-treated effluent obtained by XAD-8/XAD-4 tandem resin fractionation showed in Fig. 6(c) exhibited three fluorescence peaks, protein-like fluorescence $\left(\lambda_{\mathrm{ex}} / \lambda_{\mathrm{em}}=260-300 \mathrm{~nm} / 305-330 \mathrm{~nm}\right)$, UV fulviclike fluorescence $\left(\lambda_{\text {ex }} / \lambda_{\text {em }}=235-245 \mathrm{~nm} / 325-360 \mathrm{~nm}\right)$ and visible fulvic-like fluorescence $\left(\lambda_{\mathrm{ex}} / \lambda_{\mathrm{em}}=235-245 \mathrm{~nm} / 480\right.$ $485 \mathrm{~nm})$. The order of fluorescence intensity were proteinlike fluorophores $>$ UV fulvic-like fluorophores $>$ visible fulvic-like fluorescence, the protein-like fluorescence dominated the hydrophilics fractions and the visible fulvic-like fluorescence was negligible. After the coagulation by magnesium sulphate alone, the fluorescence intensity of protein-like and UV fulvic-like fluorophores were barely changed while visible fulvic-like fluorescence increased significantly due to the remained low-MW fulvic-like organics that can't be eliminated. Through the $\mathrm{KMnO}_{4}$ pre-oxidation stage, the protein-like and UV fulvic-like fluorescence exhibited higher intensity than that of in the bio-treated effluent and similar to the spectrum of the bio-effluent in Fig. 6(a), the visible fulvic-like fluorescence vanished completely. Nevertheless, the fluorescence intensity of protein-like and fulvic-like fluorophores were declined after the enhanced coagulation even lower than the original intensity in bio-treated effluent and after the coagulation by magnesium sulphate alone, this could be attributed to the formation of protein-like and fulvic-like organics which did not give fluorescence during the oxidation of $\mathrm{KMnO}_{4}$. 
In summary, it is concluded that compared with the magnesium sulphate coagulation, further removal of colourcaused fulvic-like and humic-like organics make the $\mathrm{ADMI}_{7.6}$ value of the effluent dropped observably after the coagulation enhanced with $\mathrm{KMnO}_{4}$. The increased low-MW hydrophilics fractions in the effluent were characterized by protein-like and UV fulvic-like organics.

\section{Conclusion}

From the above study, the following can be concluded: Compared with the treatment of magnesium sulphate coagulation alone, coagulation enhanced with $\mathrm{KMnO}_{4}$ had better $\mathrm{ADMI}_{7.6}(83 \%$ versus $72 \%)$ and DOC (40\% versus $\left.36 \%\right)$ removal under the optimal dosing conditions. Results of XAD8/XAD-4 tandem resin fractionation and molecular weight (MW) distribution measurements demonstrated that the removal of hydrophobics, transphilics and large-MW organics were improved after enhanced coagulation. Moreover, the hydrophilics and low-MW (<1 K Da) organics in the effluent of enhanced coagulation were increased by 39 and $145 \%$, respectively, which were the main reasons for inconspicuous improvement of DOC removal. Qualitative analysis on DOM with three-dimensional excitation emission matrix fluorescence spectroscopy (3-DEEMs) indicated that the colourcaused matters, fulvic-like and humic-like organics were further removed during enhanced coagulation process. Meanwhile, Protein-like and fulvic-like organics were the dominating fractions of increased low-MW hydrophilics in the effluents. In order to produce a high removal performance of the treatment, both the magnesium sulphate coagulation alone and coagulation enhanced with $\mathrm{KMnO}_{4}$ should be followed by additional steps to remove the remaining (mostly $\mathrm{MW}<1 \mathrm{~K}$ Da, hydrophilics) DOM fractions.

\section{ACKNOWLEDGEMENTS}

This study was financial supported by the National Hi-Tech Research and Development Program of China (863) (2009AA063904).

\section{REFERENCES}

1. S. Meric, D. Kaptan and T. Olmez, Chemosphere, 54, 435 (2004).

2. S.H. Lin and M.L. Chen, Water Res., 31, 868 (1997).

3. P. Vandevivere, R. Bianchi and W. Verstraete, J. Chem. Technol. Biol., 72, 289 (1998).

4. A. Pala and E. Tokat, Water Res., 36, 2920 (2002).

5. F. El-Gohary and A. Tawfik, Desalination, 249, 1159 (2009).

6. A.B. Dos Santos, F.J. Cervantes and J.B. Van Lier, Bioresour. Technol., 98, 2369 (2007).

7. S. Vanhulle, M. Trovaslet, E. Enaud, M. Lucas, S. Taghavi, D. Van Der Lelie, B.V. Aken B, M. Foret, R.C.A. Onderwater, D. Wesenberg, S.N. Agathos,Y. Schneider and A.M.Corbisier, Environ. Sci. Technol., 42, 584 (2007).
8. A.K. Verma, R.R. Dash and P. Bhunia, J. Environ. Manage., 93, 154 (2012).

9. B.H. Tan, T.T. Teng and A. Omar, Water Res., 34, 597 (2000).

10. P. Kumar, B. Prasad, M.I. Mishra and S. Chand, J. Hazard. Mater., 153, 635 (2008).

11. T.H. Kim, C. Park, E.B. Shin and S. Kim, Desalination, 161, 49 (2004).

12. D. Karadag, S. Tok, E. Akgul, K. Ulucan, H. Evden and M.A. Kaya, Ind. Eng. Chem. Res., 45, 3969 (2006).

13. P. Cañizares, F. Martínez, C. Jiménez, J. Lobato and M.A. Rodrigo, Environ. Sci. Technol., 40, 6418 (2006).

14. B. Merzouk, B. Gourich, K. Madani, C. Vial and A. Sekki, Desalination, 272, 246 (2011).

15. L. Semerjian and G. Ayoub, Adv. Environ. Res., 7, 389 (2003).

16. A. Bouyakoub, B. Lartiges, R. Ouhib, S. Kacha, A.G. El Samrani, J. Ghanbaja and O. Barres, J. Hazard. Mater., 187, 264 (2011).

17. B.Y. Gao, Q.Y. Yue, Y. Wang and W.Z. Zhou, J. Environ. Manage., 82, 167 (2007).

18. N. Li, M. Fan, J. Van Leeuwen, S. Basudeb, H.Q. Yang and C.P. Huang, J. Environ. Sci., 19, 783 (2007).

19. J.J. Chen, H.H. Yeh and I. Tseng, Environ. Technol., 29, 721 (2008).

20. L. Hu, H.M. Martin and T.J. Strathmann, Environ. Sci. Technol., 44, 6416 (2010).

22. X.R. Xu, H.B. Li, W.H. Wang and J.D. Gu, Chemosphere, 59, 893 (2005).

23. R. Liu, H. Liu, X. Zhao, J.H. Qu and R. Zhang, J. Hazard. Mater., 176, 926 (2010).

24. J. Ma, N. Graham and G. Li, J. Water Supply: Res. Technol.-Aqua, 46, 1 (1997).

25. B. Qiu, S.R. Xu and Y. Zhang, Ind. Water Waste., 37, 16 (2006) (in Chinese).

26. Y.J. Zhang, L.L. Zhou, W.Y. Li, D.Q. Li and G.B. Li, Environ. Sci., 30, 761 (2009) in Chinese.

27. C.M. Kao, M.S. Chou, W.L. Fang, B.W. Liu and B.R. Huang, Chemosphere, 44, 1055 (2001).

28. V. Correia, T. Stephenson and S. Judd, Environ. Technol., 15, 917 (1994).

29. O.J. Hao, H. Kim and P.C. Chiang, Crit. Rev. Environ. Sci. Technol., 30, 449 (2000).

30. R.F. Yu, H.W. Chen, W.P. Cheng and M.L. Chu, Environ. Monit. Assess., 118, 195 (2006).

31. F.Y. Qian, X.B. Sun, Y.D. Liu, M. Li, X.J. Li and X. Li, Ind. Water Treat., 31, 72 (2011) (in Chinese).

32. J. Croué, M. Benedetti, D. Violleau and J.A. Leenheer, Environ. Sci. Technol., 37, 328 (2003).

33. J.L. Gong,Y.D. Liu and X.B. Sun, Water Res., 42, 1238 (2008).

34. M. Li, F.Y. Qian, X.J. Li, X. Li, X.B. Sun and Y.D. Liu, Environ. Chem., 31, 88 (2012) in Chinese.

35. M. Li, X.B. Sun, Y.D. Liu, F.Y. Qian, X.J. Li and X. Li, Environ. Chem., 31, 1878 (2012) (in Chinese).

36. Z.J. Ren, Y. Sun, H. Liu, J. Ma and J. Li, Technol. Water. T, 34, 41 (2008) (in Chinese).

37. A. Baker, Environ. Sci. Technol., 36, 1377 (2002).

38. K.R. Murphy, K.D. Butler, R.G.M. Spencer, C.A. Stedmon, J.B. Boehme and G.R. Aiken, Environ. Sci. Technol., 44, 9405 (2010).

39. J. Leenheer and J. Croué, Environ. Sci. Technol., 37, 18 (2003).

40. J.R. Boehme and P.G. Coble, Environ. Sci. Technol., 34, 3283 (2000).

41. A. Baker, Environ. Sci. Technol., 35, 948 (2001).

42. J. Chen, E.J. Leboeuf, S. Dai and B.H. Gu, Chemosphere, 50, 639 (2003).

43. M.M. Dong, S.P. Mezyk and F.L. Rosario-Ortiz, Environ. Sci. Technol., 44, 5714 (2010).

44. J. Chen, B. Gu, E.J. Leboeuf, H.J. Pan and S. Dai, Chemosphere, 48, 